\title{
CONCEITO DE IDENTIDADES E A IDENTIDADE PROFISSIONAL DOCENTE
}

\author{
Alberto Albuquerque Gomes
}

Doutor em Educação pela Universidade Estadual Paulista - UNESP. Docente do Programa de Pós-graduação em Educação Universidade Estadual Paulista - UNESP. E-mail: alberto.gomes@unesp.br

\section{RESUMO}

O interesse pela temática advém de meu estágio de pós-doutoramento realizado em 2003-2004 na Universidade Lusófona de Humanidades e Tecnologia em Lisboa. Meu olhar dirigia-se para quais mecanismos ou fatores eram determinantes/decisivos/influentes na construção da identidade do profissional docente. O que significa identidade? Do ponto de vista etimológico, identidade, do latim identitate, significa: 1. Qualidade daquilo que é idêntico; 2 . Conjunto dos caracteres próprios de uma pessoa, tais como nome, profissão, sexo, impressões digitais, defeitos físicos etc., o qual é considerado exclusivo dela e, consequentemente, levado em conta, quando ela precisa ser reconhecida; consciência que uma pessoa tem de si mesma. Partindo desse pressuposto, por identidade profissional docente entendo as posições de sujeito que são atribuídas, por diferentes discursos e agentes sociais, aos professores e às professoras no exercício de suas funções em contextos laborais concretos. Refere-se ainda ao conjunto das representações colocadas em circulação pelos discursos relativos aos modos de ser e agir dos professores e professoras no exercício de suas funções em instituições educacionais, mais ou menos complexas e burocráticas. Quando tratamos de sujeitos sociais que partilham espaços, tempos e representações sociais na/sobre a escola, não podemos deixar de considerar que o contexto mais amplo em que cada um dos sujeitos está inserido interfere profundamente em suas expectativas e percepções. Assim, penso que construção da identidade docente e a concepção de profissão, é perpassada pelas formas de controle sobre o trabalho docente veiculadas pelas políticas de padronização (controle do Estado) e pelas práticas de contestação e resistência desencadeadas por docentes (sindicatos e associações docentes).

Palavras-chave: Identidade. Identidade docente. Representações sociais.

\section{CONCEPT OF IDENTITIES AND TEACHING PROFESSIONAL IDENTITY}

\begin{abstract}
The interest in this subject comes from my post-doctoral internship held in 2003-2004 at the Lusófona University of Humanities and Technology in Lisbon. My focus was directed towards which mechanisms or factors were determinant/decisive/influential for the of the teaching professional identity construction. What does identity mean? From the etymological point of view, identity, from the Latin identitate, means: 1. Quality of what is identical; 2. A set of the person's own characteristics, such as name, profession, sex, fingerprints, physical defects, etc., which is considered exclusive of it and consequently taken into account when it needs to be recognized; consciousness that a person has of himself. Based on this assumption, by professional teacher identity I understand the positions of subject that are attributed, through different discourses and social agents, to teachers in the exercise of their functions in concrete working contexts. It also refers to all the representations put into circulation by the discourses related to the ways of being and acting of teachers in the exercise of their functions in educational institutions, more or less complex and bureaucratic. When we deal with social subjects that share spaces, times and social representations in/about school, we can not fail to consider that the larger context in which each of the subjects is inserted deeply interferes with their expectations and perceptions. Thus, I think that he teacher identity construction, that is, the conception of profession, is permeated by the forms of control over the teaching work carried out by the policies of standardization (state control) and the practices of protest and resistance unleashed by teachers (unions and associations).
\end{abstract}

Keywords: Identity. Teacher identity. Social representations 


\section{INTRODUÇÃO}

O interesse por essa temática advém de meu estágio de pós-doutoramento realizado em 2003-2004, na Universidade Lusófona de Humanidades e Tecnologia em Lisboa, centrado na temática "As representações coletivas como substrato da vida social: identidade profissional, racionalidade e crise identitária do professor".

Nesse momento, intrigava-me que mecanismos ou fatores eram determinantes/decisivos/influentes na construção da identidade do profissional docente.

Este texto é um pequeno recorte da pesquisa supracitada, onde pretendo abordar, através de uma breve revisão bibliográfica, o conceito de identidade.

O que significa identidade? Ou trata-se de identidades? Esse é um conceito, um termo, uma palavra marcada pela polissemia. Do ponto de vista etimológico, identidade, do latim identitate, significa: Primeiro: Qualidade daquilo que é idêntico; Segundo: Conjunto dos caracteres próprios de uma pessoa, tais como nome, profissão, sexo, impressões digitais, defeitos físicos etc., o qual é considerado exclusivo dela e, consequentemente, levado em conta, quando ela precisa ser reconhecida; consciência que uma pessoa tem de si mesma ${ }^{1}$.

Do ponto de vista sociológico, define-se identidade como um conjunto de características pelas quais alguém ou um grupo pode ser reconhecido.

Características distintivas do carácter de uma pessoa ou o carácter de um grupo que se relaciona com 0 que eles são e com o que tem sentido para eles. Algumas das principais fontes de identidade são o gênero, a orientação sexual, a nacionalidade ou a etnicidade, e a classe social. O nome é um marcador importante da identidade individual, e dar um nome é também importante do ponto de vista da identidade do grupo. (GIDDENS, 2004, p. 694)
Segundo Dubar (2009), ainda há que se acrescentar mais uma característica: representa ao mesmo tempo, diferenciação e generalização.

[...] identidade não é o que permanece

necessariamente

"idêntico", mas o resultado de uma "identificação"

contingente. É o resultado de uma dupla operação linguageira: diferenciação e generalização. A primeira é aquela que visa a definir a diferença, o que constitui a singularidade de alguma coisa ou de alguém relativamente a alguém ou a alguma coisa diferente: a identidade é a diferença. A segunda é a que procura definir o ponto comum a uma classe de elementos todos diferentes de um mesmo outro: a identidade é o pertencimento comum. (DUBAR, 2009, p. 13)

Aponta ainda a dialética da identidade; ela é simultaneamente estável e provisória, individual e coletiva, subjetiva e objetiva, biográfica e relacional (DUBAR, 2005), o que indica que a produção das identidades resulta da convergência e intersecção dos processos biográfico (identidade para mim) e relacional (identidade para os outros).

Pensando do ponto de vista antropológico, há uma aproximação com a visão sociológica no sentido de conceber que a identidade tem simultaneamente uma dimensão individual e uma dimensão coletiva. Considerando a individualidade, a identidade refere-se à percepção que temos de nós mesmos, ou seja, as ideias e auto representações de nós mesmos. Na coletividade, confunde-se com os papéis que representamos nos diversos grupos sociais dos quais fazemos parte.

Entretanto, identidades e papéis sociais não podem ser confundidos, pois, segundo Castells (2003, p. 3),

Esses papéis (por exemplo, ser trabalhadora, mãe, vizinha, militante socialista, jogadora de basquete, frequentadora de determinada igreja e
1. Dicionário Michaelis - UOL. Disponível em: <http://michaelis.uol.com.br/>.. Consultado em 28/03/2018.$$
\text { de }
$$ 
fumadora, ao mesmo tempo) são definidos por normas estruturadas pelas instituições e organizações da sociedade [...] (enquanto que) [...] as identidades, por sua vez, constituem fontes de significado para os próprios actores, por eles originadas e construídas através de um processo de individualização.

(CASTELLS, 2003, p. 3)

Berger (2004) complementa e argumenta que a situação social na qual os sujeitos se inserem é mantida pela trama de significados carregados pelos vários atores sociais caracterizando um drama, o que sugere que sujeitos representam papéis sociais que lhes são impostos. Porém, embora a estruturação desses papéis se dê de forma exógena, ou seja, pelas instituições e organizações da sociedade, os atores, ao representarem os papéis designados 0 fazem a partir de referenciais de suas identidades, ou seja, esse modelo funciona com base em controles externos (sociais) combinados com a coação de controles internos do próprio papel desempenhado pelo(s) ator(es) de forma dissimulada ou inconsciente (identidade).

As identidades e papeis sociais se constituem a partir das trocas entre os indivíduos variando em diferentes meios sociais, nas diversas sociedades e mesmo nas mesmas sociedades em épocas diferentes. O que afinal os indivíduos trocam entre si?

Os objetos de trocas entre os indivíduos são as representações e percepções que têm sobre o mundo e que vêm compor os quadros sociais que constituem uma memória coletiva. Ou seja, não existe uma memória puramente individual e por decorrência não existe uma representação unicamente individual, pois o indivíduo vive, sobrevive e se constrói interagindo e sofrendo a ação de outros indivíduos da sociedade na qual está mergulhado através de suas diversas instâncias e situações sociais.

É dessa forma, trocando simbolicamente representações e percepções sobre o mundo que o indivíduo aprende sobre seu ambiente, numa relação orgânica ${ }^{2}$ entre indivíduo e sociedade e

\footnotetext{
2. Aqui refiro-me a processos de interação entre diferentes atores. Associo também essa relação entre esses atores como um processo associado à complexa organização social, onde associações de
}

um vínculo de processos grupais com processos comunicacionais. Parece-me que essa relação orgânica é fundamental para o processo de enraizamento, ou seja, processo através do qual o sujeito social finca raízes no grupo social ao qual pertence ou pretende pertencer.

Portanto, não faz sentido falar de identidade no singular, mas de identidades no plural e identidades dinâmicas, pois identidade(s) é/são elemento(s) de mediação entre os sujeitos e os contextos de suas vidas, revelando, portanto, sua instabilidade provocada em grande medida pelas rápidas transformações na sociedade em geral.

Ciampa (1987 apud FARIA, 2011) afirma que a identidade é metamorfose, isto é, está em constante transformação, sendo o resultado provisório da intersecção entre a história da pessoa, seu contexto histórico-social e seus projetos.

$A(s)$ identidade(s), portanto, é/são resultado do processo de socialização durante o qual os sujeitos entram em contato com as comunidades de ideias (família, escola, trabalho, religião), razão pela qual entendemos que não podemos falar de identidade, mas sim de identidades.

Considerando-se os aspectos biográfico e relacional da identidade, pode-se considerar que esta é construída a partir de uma relação entre os sujeitos, decorrente de sua capacidade de se reconhecerem e serem reconhecidos. Os sujeitos então sentem a necessidade de serem reconhecidos pelos outros. Para tanto, precisam se reconhecer. Só assim os outros o reconhecerão.

Em síntese, a(s) identidade(s) possui/em simultaneamente uma dimensão individual, isto é, as ideias, concepções e representações que construímos sobre nós mesmos; e uma dimensão coletiva, isto é, os papéis sociais que desempenhamos em cada grupo do qual pertencemos (familiar, profissional, escolar, religioso etc.); portanto,

Os modos como vivemos nossos papéis nos diferentes grupos se influenciam mutuamente, de forma que nossa identidade se constitui pela interação das

pessoas, regras, leis atuam e interagem entre si como os componentes de um organismo, e os processos ligados a esses casos também são ocasionalmente chamados orgânicos. 
especificidades desses grupos aos quais pertencemos. Isso significa que ela possui variadas dimensões, que se articulam e mudam no tempo: na verdade, não temos uma identidade, mas sim identidades. (MEKSENAS, 2003, p. 7).

Em outras palavras, o conteúdo das identidades sociais construídas no interior de um grupo social define as diversas dimensões das comparações sociais, que reforçam o sentido dessas identidades, ou seja, as identidades sociais estão marcadas pelas semelhanças entre si. Normas típicas do grupo, como atitudes e comportamentos explicitamente reconhecidos como valores coletivos, são formas relevantes de expressão da identidade de seus membros. Isso quer dizer que nossas identidades se configuram no nosso sentimento de pertença a determinados grupos levando-nos a agir prioritariamente em termos dos interesses coletivos. Como então, podemos nos reconhecer uns aos outros?

Esse reconhecer decorre das representações sociais construidas em determinado contexto, de forma que possamos partilhar com os outros um sentimento de pertencimento: pertencer a um local, a um tempo e a determinado ou determinados grupos.

Por isso cada um de nós quer ser vários num só: quero ser homem, quero ser pai, quero ser profissional, quero ser atleta. Quero ser tudo aquilo que me parece legítimo no mundo social: mas fundamentalmente, quero acreditar que ser isso ou aquilo é legítimo.

Cabe ainda dizer que, no processo de tessitura do(s) cotidiano(s) constituem-se as identidades a partir das representações sociais, enquanto experiências do senso comum, ou seja, "teorias socialmente criadas e operantes, [que] se relacionam com a construção da realidade cotidiana, com as condutas e comunicações que ali se desenvolvem, e também com a vida e a expressão dos grupos no seio dos quais elas são elaboradas". (JODELET, 2005, p. 40).

Quanto mais inserido nos contextos grupais estiver um indivíduo, tanto maior será seu compromisso com o grupo, maior será seu sentimento de pertença e mais consolidada estará sua identidade pessoal e social. Decorre que indivíduos altamente identificados com um grupo (ou grupos) tendem a agir mais em termos de "interesses coletivos", enquanto que os pouco identificados tendem a agir em termos de "interesses particulares".

Portanto, pessoas e grupos criam representações ao longo da comunicação e da cooperação. As representações, ao serem criadas, circulam, encontram-se, atraem-se, repelem-se e abrem espaço para o surgimento de novas representações, enquanto outras, mais antigas, acabam desaparecendo. Moscovici (1978) chama a atenção de que em se tratando de representações sociais, o que conta é o ser humano na condição de quem pergunta, busca respostas ou pensa e não na maneira como ele processa a informação ou se comporta.

As representações sociais seriam teorias de senso comum que ao serem internalizadas permitem a organização da realidade. A representação social tem por objetivo tornar familiar o estranho e isto é obtido, segundo Moscovici (1978) por meio da ancoragem, mediante a classificação e rotulação daquilo que não está categorizado, e através da objetivação, que consiste em transformar uma abstração em algo material, é descobrir a qualidade icônica de uma ideia.

Ao tentar estabelecer relações entre identidade-sociedade-representações sociais, penso em considerar a convergência de indivíduo e sociedade mediada pelas representações sociais. "Em suma, trata-se de tomar as representações enquanto produção, expressão e instrumento de um grupo na sua relação com a alteridade" (JODELET, 2005, p. 42), alteridade aqui entendida como o outro que apesar de ser outro possui elementos identitários que o aproxima do primeiro indivíduo.

Sobre essas aproximações, podemos utilizar como metáfora o poema de Melo Neto (2013).

Tecendo a manhã

Um galo sozinho não tece uma manhã: ele precisará sempre de outros galos. De um que apanhe esse grito que ele e o lance a outro; de um outro galo que apanhe o grito de um galo antes e o lance a outro; e de outros galos que com muitos outros galos se cruzem os fios de sol de seus gritos de galo, para que a manhã, desde uma teia 
tênue,

se vá tecendo, entre todos os galos.

E se encorpando em tela, entre todos, se erguendo tenda, onde entrem todos, no toldo (a manhã) que plana livre de armação.

A manhã, toldo de um tecido tão aéreo que, tecido, se eleva por si: luz balão.

Creio que para analisar o processo de construção das identidades sociais seja importante considerar que:

1. a concepção de tempo sugere socialização, o tempo no qual os sujeitos realizam os atos necessários para assegurar a sobrevivência individual e grupal;

2. a concepção de espaço sugere que os tempos de socialização requerem a determinação de espaços onde isso deve ocorrer como forma de disciplinamento das relações sociais;

3. a construção das identidades, pois, decorre da intersecção entre tempo e espaço, mediada pelas representações sociais que os sujeitos-atores desse tempo-espaço são capazes de construir e partilhar entre si.

Assim, tal como sugere Melo Neto (2013), precisamos dos outros galos que apanhem nossos cantos, lancem-nos a outros, mas também nos devolvam esses cantos com novos cantos como que para a composição de uma sinfonia, que embora composta de muitas vozes, possa ser apropriada e compreendida por cada galo dando vida e sequência às nossas manhãs.

\section{Identidade profissional docente}

Por identidade profissional docente entendem-se as posições de sujeito que são atribuídas, por diferentes discursos e agentes sociais, aos professores e às professoras no exercício de suas funções em contextos laborais concretos. Refere-se ainda ao conjunto das representações colocadas em circulação pelos discursos relativos aos modos de ser e agir dos professores e professoras no exercício de suas funções em instituições educacionais, mais ou menos complexas e burocráticas. (GARCIA; HIPÓLITO; VIEIRA, 2005)

Reafirmando as ideias explicitadas no trecho acima, entendo por identidade profissional docente aquela identidade construída pelos professores a partir de posições de sujeito que são atribuídas, pelos diferentes discursos e agentes sociais.

Alguns autores que tratam dessas questões como Nóvoa (1992); Sarmento (1999) e Arroyo (2001) têm destacado em seus estudos temas como a autonomia profissional, proletarização e características de profissionalismo dos docentes que têm sido problematizados.

No final da década de 1980, o principal debate sobre a profissão docente era em torno da conceituação de classe social e sobre a natureza do trabalho docente, principalmente com a publicação de alguns artigos que demarcaram e estimularam as discussões (APPLE, 1987; 1988; ARROYO, 1985). Debatia-se, então, se professores e professoras realizavam um trabalho produtivo ou improdutivo ou, em outras palavras, se a natureza do trabalho que realizavam era capitalista ou não, e se pertenciam, como grupo social, à classe trabalhadora ou à classe média, como tradicionalmente haviam sido considerados até então por estudos sociológicos clássicos.

Alguns trabalhos se apoiaram nas concepções de gênero e classe social para uma interpretação do trabalho docente no Brasil (HYPOLITO, 1994; 1997; VIEIRA, 1992). A análise da gênese histórica dessa categoria profissional no Brasil considera aspectos da composição social e da natureza de classe do magistério, considerando a dificuldade de enquadramento do professor como componente de uma classe trabalhadora ou classe média (HYPOLITO, 1994). Vários autores/autoras (HYPOLITO, 1994; 1997; DEMARTINI; ANTUNES, 2002; VIANNA, 2002; FAGUNDES, 2005; CHAMON, 2006; LOURO, 1998, $2003,2007)$ têm focado seus estudos no esforço de compreender o processo de feminização do magistério e o impacto na formação da identidade docente. 
Coimbra, Gonçalves e Rodrigues (2010, p. 4) argumentam que

\begin{abstract}
O processo que podemos chamar de feminização do magistério tem sido frequentemente justificado por linhas essencialistas, associandose supostas características das mulheres às necessidades da docência, notadamente na educação básica. No imaginário popular, as mulheres têm vocação para o magistério, por sua amorosidade, dedicação e inclinação maternal, isto está associado também a uma visão mistificada do processo educativo.
\end{abstract}

Essas são representações que, dentre outras como dom, vocação, sacerdócio etc., (HYPÓLITO, 1997; ARCE, 2001; CERISARA, 2002; GOMES, 2008) exercem forte influência na consolidação da identidade profissional do professor e permitem estabelecer algumas relações entre a construção da identidade profissional e representações sociais considerando-as como manifestações de indivíduos e grupos ao longo dos processos comunicacionais que asseguram aos sujeitos sociais uma compreensão congruente acerca da realidade social. Ou seja, a inserção dos indivíduos no mundo social e a interação entre os diferentes sujeitos ocorrem com base em sistemas de representações e atitudes (religião, moral, normas jurídicas, educação, identidades e papéis sociais) que asseguram canais de via dupla para a comunicação.

Sobre esses processos, Durkheim argumentava que consistiam em representações coletivas resultantes das relações entre os indivíduos que deveriam ser examinadas distinguindo-as dos fenômenos psicológicos de caráter individual, pois os estados da consciência coletiva são de natureza diferente dos estados da consciência individual; são representações de outra espécie [...] pois "[...] o que as representações coletivas traduzem é a maneira pela qual o grupo se enxerga a si mesmo nas relações com os objetos que o afetam". (DURKHEIM, 1977, p. 26).
Essas representações poderiam ser exemplificadas através da linguagem ou de práticas de trabalho desenvolvidas no interior de uma dada sociedade, produtos reais das relações sociais. Portanto, as representações decorrentes das relações estabelecidas entre indivíduos ou entre grupos secundários podem ser entendidas como abstrações que formulamos frequentemente, como por exemplo, em Economia, em Sociologia ou em Psicologia, constituindo-se em substrato da vida social.

Como se vê, uma representação social possui uma força que repercute de maneira significativa na constituição do indivíduo e do sujeito social reforçando comportamentos socialmente aceitos e reprovando comportamentos inadequados.

Portanto, a construção da identidade profissional do professor pode ser compreendida como processo de inserção e aceitação social. Autoridade moral reconhecida na figura do professor, a crença do próprio professor na relevância dessa autoridade são elementos que nos permitem considerar que sejam fulcrais na legitimação do professor revelando uma simbiose entre biografia individual e aspectos relacionais.

\section{As condições contemporâneas da identidade docente: crise de identidade do professor?}

Apesar de ser habitado por seres dotados de vontade e capazes de se narrarem e de se transformarem nas narrativas que produzem sobre si próprios, o campo educativo, o ter-se em conta os estudos que são produzidos a seu propósito, parece ser estruturado por um conjunto de entidades onde estes seres estão ausentes ou têm o sentido da sua existência exclusivamente dependente das relações que estabelecem com estas entidades. A ter-se em conta estes estudos, com efeito, os modos de existência dos professores reduzir-se-iam às representações que eles têm dos currículos escolares, das escolas, dos 
sistemas de formação que os envolvem ou das suas propriedades

socioculturais, da mesma forma que as propriedades socioculturais das famílias dos alunos, a sua participação ou a representação que têm da escola ou as expectativas escolares dos alunos ou das suas famílias definiram os modos de existência dos alunos ou dos jovens na escola. (CORREIA; MATOS, 2001, p. 11)

O trecho do texto destacado acima revela as dificuldades pelas quais passa o professor em seu cotidiano profissional e na construção e consolidação de sua identidade profissional.

O processo de construção das identidades profissionais dos professores iniciouse num ambiente de transformação, auge da revolução científica, quando novos espaços foram ocupados pelos sujeitos, inseridos no novo modelo urbano industrial que exigiu a construção de novas identidades sustentadas pelo paradigma da racionalidade. Dessa perspectiva de análise, sugeriu-se como hipótese norteadora que tais identidades são construídas ancoradas por representações sociais e, consequentemente, a profissionalização e a construção de identidades específicas para cada tipo de trabalhador são mecanismos eficientes para assegurar o controle dos sujeitos. Portanto, profissionais como os professores tornaram-se imprescindíveis para o estabelecimento dessa nova ordem social. Assim sendo, a representação sobre ser professor é vinculada à figura do profissional regulador da ordem social, o que sugere a seguinte reflexão: a profissionalização e a escolarização são exigências da modernidade como forma de inserção dos indivíduos no mundo social e ao mesmo tempo de regulação das ações sociais.

Essas novas exigências são marcadas pelas primeiras preocupações com a moralização e educação da criança que ensejam uma nova visão a respeito desta. Ao contrário da Sociedade Feudal, onde a criança era vista como um adulto em miniatura, incorporada ao trabalho tão logo alcançasse aptidão para tal, na nascente Sociedade Burguesa a criança é vista como ser que necessita de cuidados, de escolarização e de preparação para sua inserção no mundo adulto, embora sua incorporação ao mundo do trabalho industrial contradissesse esse discurso.

Durkheim em "Sociologia, educação e moral" ${ }^{1}$ afirma que a escola pode produzir nas crianças efeitos morais fundamentais para a sua inserção no mundo adulto.

$\mathrm{Na}$ escola, com efeito, existe todo um sistema de regras que predeterminam o comportamento da criança. Esta deve frequentar as aulas com regularidade, deve comparecer à hora marcada, com uma apresentação e um porte convenientes; durante a aula, não deve perturbar a ordem; após haver aprendido as lições deve fazer as suas obrigações, e faze-las com a aplicação necessária... O conjunto desses deveres constitui aquilo a que chamamos a disciplina escolar. É pela prática da disciplina escolar que é possível inculcarmos na criança o espírito da disciplina. (DURKHEIM, 1961, p. 251)

Como podemos observar, na concepção de Durkheim, a educação da criança deveria funcionar como uma forma de controle e disciplinamento. Esse, entre outros, são os primeiros sinais emitidos ao final do século XIX e início do século XX sobre como deveria funcionar a educação das crianças.

Entretanto, o contexto no qual se construiu o ideal de escola pública e da profissão de professor revela-se muito distante do contexto contemporâneo. A condição da escola mudou (democratização e acesso universal), o perfil da profissão de professor mudou (exigências de cumprimento de novas tarefas, secundarização da educação, domínio de novas habilidades e competências etc.).

Os impactos da reconfiguração do mundo contemporâneo, especialmente ao longo da última década do século $X X$ e primeira década do século XXI evidenciam-se nas representações cada vez mais negativas sobre a função docente. A escola, tradicionalmente marcada pelas possibilidades de ascensão social e de superação das desigualdades sociais, tinha no professor a 
imagem da autoridade constituída capaz de conduzir jovens e crianças ao convívio social e à vida em democracia. Essas práticas democráticas são marcadas pelas formas como os sujeitos as representam socialmente; a escola e os professores têm um papel fundamental na construção dessas práticas.

Além dos aspectos apontados acima, pode-se encontrar também várias repercussões advindas de outras mudanças pelas quais passa o mundo contemporâneo como as novas Tecnologias de Informação e Comunicação (TIC), a informática educativa, a terceirização de alguns serviços educacionais próprios do contexto escolar como limpeza e manutenção do espaço físico escolar, serviços administrativos essenciais como meio de realização do trabalho docente, segurança das escolas, além da precarização do trabalho docente ${ }^{3}$.

Portanto, podemos falar de uma crise mais ampla, para além da crise de identidade do professor apontada por vários autores, dentre eles Correia e Matos (2001), Dubar (2009), Gomes (2013) e Law (2001).

Sanfelice (1996, p. 5), ao analisar a "crise da educação brasileira" afirma que:

Já há algum tempo, tenho
insistido e repetido de
forma mais ou menos
exaustiva, principalmente
em aulas, palestras e
conferências, que não
compartilho das idéias
muito generalizadas de
que em se tratando de
educação brasileira, tudo,
mas absolutamente tudo
se encontra em crise.
Menos ainda sou favorável
às ideias subjacentes a
esta visão de crise que,
com frequência, leva ao
imobilismo, à falta de
perspectivas e mesmo a
uma acomodação da
situação.

Em outras palavras, antes de afirmarmos peremptoriamente que há uma crise de

\footnotetext{
3. Sousa (2003) em pesquisa realizada junto a um grupo de professores organizados em cooperativa de prestação de serviços educacionais na cidade de Três Lagoas, Mato Grosso do Sul aponta um movimento de precarização do trabalho docente através de um processo de terceirização do trabalho docente: nesse caso específico, o professor não é mais funcionário da escola, mas prestador de serviços.
}

identidade do professor, precisamos considerar a questão numa perspectiva mais ampla como nos sugere Lopes (2001b).

A mesma autora ainda comenta que embora desde o último quarto de século $X X$ os termos identidade e crise de identidade já sejam frequentemente referidos, somente na contemporaneidade, tem merecido mais atenção e tem proliferado os estudos sobre os temas,

Es en la segunda mitad de la década de 1980 y en el inicio de la década de 1990 cuando los términos «identidad» y «crisis de la identidad» comienzan a ser profusamente utilizados, ya sea a propósito de los profesores como de otros grupos y entidades sociales y culturales. Aunque existía una gran distancia entre el uso del término y su conceptualización, como sucede hoy en día [...] los estudios sobre la identidad proliferaban en los trabajos científicos de la Psicología Social y de la Ego Psychology, así como también de la Sociología y de la Antropología. Esta extensión del uso del concepto, que de estrictamente psicológico había pasado a lugar de convergencia de las ciencias sociales $y$ humanas, se acompañaba de su propia revisión conceptual [...] (LOPES, 2007, p. 3$)^{4}$

Como decorrência da hipótese formulada acima, tal crise pode ser associada ao esgotamento de um modelo de identidade construído com base no paradigma da

\footnotetext{
${ }^{4}$. É na segunda metade da década de 1980 e o início da década de 1990 quando os termos "identidade" e "crise de identidade" começaram a ser amplamente utilizados, tanto sobre os professores e outros grupos e organizações sociais e culturais. Embora tenha havido uma grande diferença entre o prazo e sua conceituação, como ocorre hoje [...] estudos de identidade proliferaram no trabalho científico da Psicologia Social e Psicanálise, assim como Sociologia e Antropologia. Esta extensão do uso do conceito, estritamente psicológica foi um espaço de convergência entre as ciências sociais e humanas, acompanhado de sua própria revisão conceitual [...] (LOPES, 2007, p. 3). Tradução livre do autor.
} 
racionalidade científica emergente a partir da revolução científica dos séculos XVI-XVIII tornando-se um modelo global. Ou seja, não só as identidades profissionais se deterioram, mas também o modelo de racionalidade que dirigiu o mundo nos últimos três séculos.

Segundo a autora, a crise na verdade atinge a toda a vida social, atingindo também o professor em função da natureza específica do seu trabalho.

Por conseguinte, as mudanças na sociedade contemporânea têm sido consideradas frequentemente como indicadores de uma "crise". Se de fato, a sociedade contemporânea estiver sob o signo da crise, a compreensão desta crise passa por uma análise das consequências das transformações dessa sociedade.

Segundo Lopes (2001b, p. 33),

O projecto da modernidade

é um projecto

revolucionário, mas, portador de contradições profundas para as quais não possuía os meios de convívio, realizou-se excedendo-se nuns aspectos e definhando-se noutros [...] Neste processo, o capitalismo teve um papel catalizador, mas não fundador, esse coube à religião; a grelha de execução, entretanto, coube à ciência; fundado na complementaridade e harmonia entre emancipação e regulação, o projecto da modernidade faz da ciência racional a sua principal estratégia de realização social.

Essa indicação de Lopes (2001) nos permite pressupor que a "moderna profissão docente" se consolida profundamente ligada à sociedade moderna, e, portanto, a crise de identidade se torna mais pronunciada, porque a sociedade está em profunda transformação. Não há aqui nenhuma sugestão de que a sociedade tenha atingido algum patamar de ordem e que a partir de dado momento histórico entrou em crise. $\mathrm{O}$ que queremos dizer é que a sociedade contemporânea vive transformações mais agudas que colocam em questão $o$ projeto $d a$ modernidade.
Quando trato de sujeitos sociais que partilham espaços, tempos e representações sociais na/sobre a escola, não é possível deixar de considerar que o contexto mais amplo em que cada um dos sujeitos está inserido interfere profundamente em suas expectativas e percepções.

Quero dizer com isso que a antiga imagem de um professor como símbolo da autoridade e da providência moral tem sido substituída pela imagem de um adversário a ser derrotado pelo aluno, como se ambos fossem opositores; a imagem da escola como ambiente seguro onde crianças e jovens poderiam desenvolver os valores morais e democráticos é substituída pela imagem de um território conflagrado; a imagem do aluno como aprendiz dócil a ser encaminhado para vida em sociedade é substituída pela imagem de um aluno rebelde, problemático, portador de todos os vícios e de nenhuma virtude. Os extremos dessas "representações" não deixam dúvidas de que as expectativas em relação à escola, alunos e professores mudaram radicalmente. A representação de "ser professor" assume outros sentidos para os quais nem sempre os candidatos ao magistério estão devidamente preparados (GOMES, 2008).

\section{CONSIDERAÇÕES FINAIS}

As mudanças estão ancoradas em três aspectos: 1 . a identidade dos professores deve ajustar-se à concepção de educação da nação; 2 . uma das formas de acompanhar a escola e os professores é a criação de mecanismos, através do discurso oficial, que sejam capazes de monitorar a identidade dos professores; 3 . a identidade de professores pode, de forma subreptícia, ser manobrada a favor de interesses que não são necessariamente dos próprios professores e dos demais sujeitos que partilham o espaço escolar. (LAW, 2001).

Embora o Estado exerça controle sobre as ações do professor e a construção de sua identidade através de mecanismos institucionais, podemos tomar como referência Lima (1991, p. 141) que nos sugere que "a imposição normativa externa e o normativismo ocorrerão, em simultâneo, com fenómenos de infidelidade normativa e de fuga do normativismo através da intervenção dos actores escolares" (grifo nosso), ou seja, as questões expostas acima, indicam uma forma sútil e furtiva de controle das ações do professor e indiretamente dos demais sujeitos 
que partilham do espaço escolar enquanto que simultaneamente, o professor, individual ou coletivamente, resiste a essa opressão.

Assim, para pensar numa ( $\mathrm{re}$ ) construção da identidade docente, ou seja, a reinvenção da profissão, tanto as formas de controle sobre o trabalho docente veiculadas pelas políticas de padronização (controle do Estado) quanto as práticas de contestação e resistência desencadeadas por docentes (sindicatos e associações docentes) precisam ser revistas pelos sujeitos que constroem suas identidades: os próprios professores.

\section{REFERÊNCIAS}

APPLE, Michael Whitman. Relações de classe e de gênero e modificações no processo de trabalho docente. Cadernos de Pesquisa, São Paulo, n. 60, p. 3-14, fev. 1987.

APPLE, M. Ensino e trabalho feminino: uma análise comparativa da história e ideologia. Cadernos de Pesquisa, São Paulo, n. 64, p. 14-23, 1988.

APPLE, Michael Whitman. Entre o neoliberalismo e o neoconservadorismo: a educação e conservadorismo em um contexto global. In: BURBULES, N. C.; TORRE, C. A. (Ed.). Globalização $e$ educação: perspectivas críticas. Tradução de Ronaldo Cataldo Costa. Porto Alegre: ArtMed, 2004. p. 45-57.

ARCE, Alessandra. Documentação oficial e o mito da educadora nata na educação infantil. Cadernos de Pesquisa. São Paulo, n.113, jul. 2001.

ARROYO, Miguel. Ofício de mestre: imagens e auto-imagens. 3. ed. Petrópolis: vozes, 2001.

ARROYO, Miguel. . Mestre, professor, trabalhador. Belo Horizonte: FE-UFMG, 1985.

BERGER, Peter. L., LUCKMANN, Thomas. A Construção social da realidade. 23. ed. Petrópolis, 2004.

CASTELLS, Manuel. O poder da identidade. Lisboa: Fundação Calouste Gulbenkian, 2003.

CERISARA, Ana Beatriz. Professoras de educação infantil: entre o feminino e o profissional. São Paulo: Cortez, 2002.
CHAMON, Magda. Trajetória de feminização do magistério e a (con)formação das identidades profissionais. In: SEMINÁRIO DA REDESTRADO REGULAÇÃO EDUCACIONAL E TRABALHO DOCENTE., 6., Rio de Janeiro. Anais... Rio de Janeiro: UERJ, 2006.

COIMBRA, Kellen Regina Moraes, GONÇALVES, Maria de Fátima da Costa e RODRIGUES, Fernanda Lopes. Reflexões sobre a feminização do magistério.In: SEMINÁRIO DE SOCIOLOGIA \& POLÍTICA, 2., Curitiba. Anais... Curitiba: UFPR, $2010 . \quad$ Disponível em www.seminariosociologiapolitica.ufpr.br. Acesso em: 02 abr. 2013.

CORREIA, José Alberto; MATOS, Manuel. Solidões e solidariedades nos quotidianos dos professores. Porto: Asa, 2001.

DEMARTINI, Zeila de Brito Fabri; ANTUNES, Fátima. Magistério primário: profissão feminina, carreira masculina. In.: CAMPOS, Maria Christina Siqueira de Souza; SILVA, Vera Lucia Gaspar da (Org.). Feminização do magistério: vestígios do passado que marcam o presente. Bragança Paulista: EDUSF, 2002.

DUBAR, Claude. A sociologia do trabalho ante a qualificação e a competência. Educação \& Sociedade, Campinas, v. 19, n. 64, p. 87-103, set. 1998. Disponível em $<$ http://www.cedes.unicamp.br $\geq$. Acesso em: 08 abr. 2013.

DUBAR, Claude. A socialização: construção das identidades sociais e profissionais. Porto: Porto Editora, 2005.

DUBAR, Claude. A crise das identidades: A interpretação de uma mutação. São Paulo: Edusp, 2009.

DUBAR, Claude. La socialisation: Construction dês identités sociales e professionnelles. Paris, Armand Colin, 1991.

DURKHEIM, Emile. Sociologia e Filosofia. Rio de Janeiro: Forense, 1977.

DURKHEIM, Emile. Sociologia, educação e Moral. Trad. Evaristo Santos. Porto: RES - Editora, 1961. 
FAGUNDES, Tereza Cristina Pereira Carvalho. Mulher e Pedagogia: um vínculo ressignificado. Salvador: Helvécia, 2005.

FARIA, Ederson; SOUZA, Vera Lúcia Trevisan de. Sobre o conceito de identidade: apropriações em estudos sobre formação de professores. Revista Semestral da Associação Brasileira de Psicologia Escolar e Educacional, São Paulo, v.5, n.1, p.5-42, Jan./Jun. 2011.

GARCIA, Maria Manuela Alves; HYPOLITO, Álvaro Moreira; VIEIRA, Jarbas Santos. As identidades docentes como fabricação da Docência. Educação e Pesquisa, São Paulo, v. 31 , n. 1, p. 45-56, jan./abr. 2005. DOI: 10.1590/S151797022005000100004. Disponível em: http://www.scielo.br/scielo.php?script=sci_arttex t\&pid=S1517-

97022005000100004\&lng=pt\&tlng=pt. Acesso em:

GIDDENS, Anthony. Sociologia. 4. ed. Lisboa: Fundação Calouste Gulbenkian, 2004.

GOMES, Alberto A. A construção da identidade profissional do professor: uma análise de egressos do curso de Pedagogia. IN: Anais do VI CONGRESSO PORTUGUÊS DE SOCIOLOGIA, 6., Local. Anais... Lisboa, 2008. Disponível em <http://www.aps.pt/vicongresso/pdfs/590.pdf $>$. acesso em: 02 abr. 2013.

HYPOLITO, A. M. Processo de trabalho na escola: uma análise a partir das relações de classe e de gênero. 1994. Dissertação (Mestrado) Universidade Federal de Minas Gerais, Belo Horizonte. 1994.

HYPÓLITO, Álvaro Moreira. Trabalho docente, classe social e relações de gênero. Campinas: Papirus, 1997.

HYPOLITO, Álvaro Moreira et al. Trabalho docente, profissionalização e identidade: contribuições para a constituição de um campo de estudo. Educação em Revista, Belo Horizonte, n.37, p.123-138, jul.2003.

JODELET, Denise. Loucuras e representações sociais. Rio de Janeiro: Vozes, 2005.
LAW, M. Os professores e fabricação das identidades. Currículo sem fronteiras. v. 1, n. 2, pp. 117-130, jul/dez, 2001.

LIMA, Licinio C. Produção e reprodução de regras: normativismo e infidelidade normativa na organização escolar. Inovação. v.4, n. 2/3, 1991.

LOPES, Amélia. Mal-estar na docência? Visões, razões e soluções. Lisboa: Cadernos do Criap/Asa, 2001a.

LOPES, Amélia. Libertar o desejo, resgatar a inovação: A construção de identidades profissionais docentes. Lisboa: Instituto de Inovação Educacional, 2001b.

LOPES, Amélia. Professora e identidade: Um estudo sobre a identidade social de professores portuguesas. Porto: ASA, v.25. 2001c (Cadernos Investigações e práticas)

LOPES, Amélia. La construcción de identidades docentes como constructo de estructura y dinámica sistémicas: argumentación y virtualidades teóricas y prácticas Profesorado. Revista de currículum y formación del profesorado, v.11, n.3, 2007. Disponível em http://www.ugr.es/local/recfpro/rev113COL1.pdf . Acesso em: 29 ago.

2013.

LOURO, Guacira L. Mulheres na sala de aula. In. PRIORE, Mary Del (org); BUSSANEZI, Carla (coord. de textos). História das mulheres no Brasil. 8. ed. São Paulo: Contexto, 2006.

LOURO, Guacira L. Gênero e Magistério: Ideidade, História e Representação. In.: Docência, Memória e Gênero: estudos sobre formação. São Paulo: Escrituras, 2003.

LOURO, Guacira L. Gênero, sexualidade $e$ educação: uma perspectiva pós-estruturalista. Petrópolis, Rio de Janeiro: Vozes, 1998.

MEKSENAS, Paulo. Existe uma origem da crise de identidade do professor? Revista Espaço Acadêmico, n. 31, dez./2003. Disponível em http://www.espacoacademico.com.br/031/31cm eksenas.htm. Acesso em: 23 mar. 2008.

MELO NETO, João Cabral. Tecendo a manhã. Jornal da poesia. Disponível em 
http://www.revista.agulha.nom.br/joao02.html.

Acesso em: 02 abr. 2013.

MOSCOVICl, Serge. A representação social da psicanálise. Rio de Janeiro: Zahar Editores, 1978.

MOSCOVICl, Serge. S. Representações sociais. Investigações em psicologia social. São Paulo: Vozes, 2003.

NÓVOA, António. (Org.) Vidas de professores. Porto: Porto Editora, 1992.

SARMENTO, Teresa. Identidade profissional de educadores de infância. Cadernos de Educação de Infância, n.52, p.12-26, 1999.

SOUSA, Vera Luísa de. A trajetória de docentes no novo mundo do trabalho: resgatando algumas identidades. 2003. 122 f. Dissertação (Mestrado em Educação) Universidade Estadual Paulista Júlio de Mesquita Filho, Presidente Prudente, 2003.

VEIGA, Ilma Passos Alencastro. Avanços $e$ equívocos na profissionalização do magistério e a nova LDB. Campinas, Papirus, 1998.

VIANNA, Claudia. Contribuições do conceito de gênero para a análise da feminização do magistério no Brasil. In. CAMPOS, Maria Christina Siqueira de Souza; SILVA, Vera Lucia Gaspar da (Org.). Feminização do magistério: vestígios passados que marcam o presente. Bragança Paulista: EDUSF, 2002.

Recebido para avaliação: 10/09/2018

Revisado em: 13/12/2018

Aceite Final: 13/12/2018 